\title{
Fabrication of Epoxide Functional Hydrophobic Composite Polymer Particles by Suspension Polymerization and Subsequent Doping with $\mathrm{Fe}_{3} \mathrm{O}_{4}$ Nanoparticles
}

\author{
R. Shabnam ${ }^{1}$, M. A. Rahman ${ }^{1}$, M. A. J. Miah ${ }^{1}$, M. K. Sharafat ${ }^{1}$, H. M. T. Islam ${ }^{2}$, M. M. \\ Rahman $^{1}$, M. A. Gafur ${ }^{3}$, H. Ahmad ${ }^{1^{*}}$ \\ ${ }^{1}$ Department of Chemistry, Rajshahi University, Rajshahi 6205, Bangladesh \\ ${ }^{2}$ Department of Chemistry, Begum Rokeya University Rangpur, Rangpur 5400, Bangladesh \\ ${ }^{3}$ Pilot Plant and Process Development Centre, BCSIR, Dhaka 1205, Bangladesh
}

Received 6 March 2017, accepted in final revised form 2 July 2017

\begin{abstract}
This investigation described a simple three-step process for the fabrication of micrometersized magnetic composite polymer particles. This composite polymer particle consisted of crosslinked hydrophobic poly(lauryl methacrylate-divinyl benzene) (P(LMA-DVB)) core, prepared by suspension polymerization. Then, P(LMA-DVB) copolymer core particles were coated with poly(glycidyl methacrylate) (PGMA) by seeded polymerization to introduce epoxide functionality. Finally, P(LMA-DVB)/PGMA composite particles were doped with iron oxide $\left(\mathrm{Fe}_{3} \mathrm{O}_{4}\right)$ nanoparticles following in situ co-precipitation of $\mathrm{Fe}^{2+}$ and $\mathrm{Fe}^{3+}$ from their alkali aqueous solution. The presence of strained oxirane ring derived from PGMA segment present at the surface is expected to induce high affinity towards precipitated magnetic $\mathrm{Fe}_{3} \mathrm{O}_{4}$ nanoparticles. The compositional structure of $\mathrm{P}(\mathrm{LMA}-$ DVB)/PGMA/ $/ \mathrm{Fe}_{3} \mathrm{O}_{4}$ composite polymer particles was confirmed by Fourier Transform IR (FTIR), electron microscopy, thermogravimetry (TG), X-ray diffraction (XRD) and energydispersive X-ray (EDX).
\end{abstract}

Keywords: Epoxide functionality; Hydrophobic; Doping; $\mathrm{Fe}_{3} \mathrm{O}_{4}$; Composite particles.

() 2017 JSR Publications. ISSN: 2070-0237 (Print); 2070-0245 (Online). All rights reserved.

doi: http://dx.doi.org/10.3329/jsr.v9i3.31811 J. Sci. Res. 9(3), 329-339 (2017)

\section{Introduction}

Micrometer-sized hydrophobic latex particles find extensive uses such as resins for chromatographic separation, water purification, oil absorbency agents, viscosity modifiers, oil-soluble drag reducers etc. [1-4]. During the last few years we have developed techniques to prepare variable-sized latex particles ranging from nano to several microns from lauryl methacrylate (LMA) a highly hydrophobic monomer because

\footnotetext{
*Corresponding author: samarhass@yahoo.com; hahmad@ru.ac.bd
} 
of its long chain alkyl group. The poor water solubility of LMA $\left(<<0.01 \mathrm{~g} / 100 \mathrm{~g}\right.$ at $\left.25^{\circ} \mathrm{C}\right)$ prevents this monomer from being polymerized by conventional emulsion polymerization and the conversion is often very low [5]. In a recently published article we proposed modified emulsion copolymerization of LMA and methyl methacrylate (MMA) to produce sub-micrometer sized latex particles in a dispersion medium comprising waterethanol mixture using water soluble initiator [6]. Ethanol was used to improve the solubility of LMA in water, a prime requirement for emulsion polymerization. The effect of third monomer on the overall emulsion terpolymerization of LMA and MMA was also investigated in terms of time-conversion graphs, morphology and size of particles [7]. Preparation of PLMA homopolymer latex particles by suspension polymerization using poly (vinyl alcohol) (PVA) as steric stabilizer was also reported [8]. The polymerization produced increased coagulation because of soft and flexible structure resulted from low glass transition temperature of PLMA [9]. To overcome this problem the author successfully carried out suspension copolymerization of LMA with high amount of divinyl benzene (DVB) as cross-linker in stable isolated droplets containing either n-hexadecane (HD) or HD-toluene (HD-T) or toluene as a non-solvent for the resulting $\mathrm{P}(\mathrm{LMA}-\mathrm{DVB})$ copolymer [10]. In that case, the non-solvent-copolymer combinations produced variation of the internal morphology of polymer particles. In another investigation, the author proposed a novel way to prepare magnetic nanocomposite particles coated with highly cross-linked PLMA layer and evaluated their usefulness as adsorbent for removing organic pollutants from water [11]. In a relatively recent investigation the author investigated the suitability of activated swelling method for preparing several micrometer-sized polystyrene (PS)/PLMA-DVB) composite polymer particles [12]. However, this swelling method was not helpful for the preparation of monodispersed particles though the average size was in the micrometer range. These composite particles were functionalized with epoxide groups and applied for the removal of dye molecules from water solution to see the cumulative effect of functionality and hydrophobicity on adsorption behavior. In the present investigation, we used a simple suspension polymerization to prepare cross-linked P(LMA-DVB) composite particles. The prepared micrometer-sized particles were then functionalized with epoxide groups via seeded polymerization with poly (glycidyl methacrylate) (PGMA). The surface of prepared $\mathrm{P}(\mathrm{LMA}-\mathrm{DVB}) / \mathrm{PGMA}$ composite particles were then modified to prepare magnetically doped composite particles via complexation of $\mathrm{Fe}_{3} \mathrm{O}_{4}$ nanoparticles with epoxide functionality [13]. A detail scheme for the preparation of P(LMA$\mathrm{DVB} / \mathrm{PGMA} / \mathrm{Fe}_{3} \mathrm{O}_{4}$ composite particles is shown in Fig. 1. These composite particles can find application as good adsorbent for the removal of toxic metal ions from polluted water because $\mathrm{Fe}$ (III)-bearing materials are known to have high selectivity and affinity for many metal ions compared to other conventional adsorbent materials like activated carbon, soil, resin and alumina [14-16]. The highly reactive epoxide functionality can also be used either directly or through modification to immobilize biopolymers, drugs, dyes and other sensitive compounds [17-21]. 


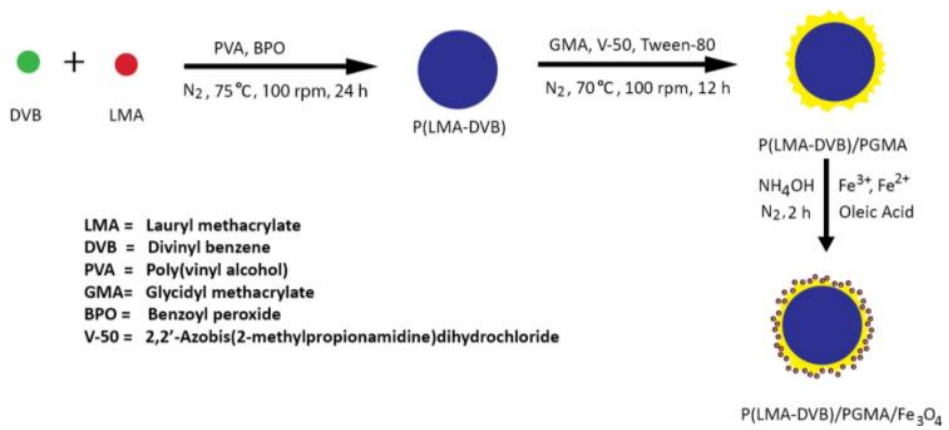

Fig. 1. Scheme for the preparation of $\mathrm{P}(\mathrm{LMA}-\mathrm{DVB}) / \mathrm{PGMA} / \mathrm{Fe}_{3} \mathrm{O}_{4}$ composite polymer particles.

\section{Experimental}

\subsection{Chemicals and instruments}

LMA from Fluka Chemika (Switzerland) was repeatedly rinsed with $10 \% \mathrm{NaOH}$ aqueous solution to remove any inhibitor and then passed through activated basic alumina in a column chromatography. Crosslinking agent DVB (80\% grade) from Sigma-Aldrich, Chemie (USA) was purified with aqueous $10 \% \mathrm{NaOH}$ solution and subsequently dehydrated by stirring with anhydrous $\mathrm{CaCl}_{2}$. Benzoyl peroxide (BPO) from BDH Chemicals Ltd. (UK) was recrystallized from methanol and preserved in the refrigerator before use. Poly(vinyl alcohol) (PVA) from Thomas Baker Chemicals Limited (India) of molecular weight $1.4 \times 10^{4} \mathrm{gmol}^{-1}$ was used as polymeric stabilizer. Ferric chloride hexahydrate $\left(\mathrm{FeCl}_{3} \cdot 6 \mathrm{H}_{2} \mathrm{O}\right)$, ferrous sulfate $\left(\mathrm{FeSO}_{4}\right), \mathrm{NH}_{4} \mathrm{OH}$, oleic acid and other chemicals were of analytical grade. Deionized water was distilled using a glass (Pyrex) distillation apparatus.

Scanning electron microscopy, SEM was performed to see the particle size distribution with a SU8000 microscope (Hitachi, Japan) operating at a voltage of $20 \mathrm{kV}$. Energy dispersive X-ray (EDX) spectral analyses were also performed (SU8000) to confirm the elemental composition. FTIR (Perkin Elmer, FTIR-100, USA); X-ray diffractometer (Rigaku Ultima IV RINT D/max-kA, Japan), and thermogravimetry with a TGA EXSTAR-6000 (Seiko Instrument Inc., Japan) were used for the characterization of the latex particles.

\subsection{Preparation of crosslinked P(LMA-DVB) core particles}

$3 \mathrm{~g}$ of each LMA and DVB, $1.2 \mathrm{~g}$ of PVA and $0.12 \mathrm{~g}$ of BPO were taken in a $100 \mathrm{~mL}$ stopper bottle. $20 \mathrm{~mL}$ distilled water was added and the mixture was magnetically stirred at $2000 \mathrm{rpm}$ for $1 \mathrm{~h}$ at $20^{\circ} \mathrm{C}$ to form microdroplets. In order to emulsify completely the monomer mixture was further homogenized by a homogenizer (Digital Ultra Turrax, IKA, Germany) at 20,000 rpm for $3 \mathrm{~min}$ in ice-water bath. The homogenized mixture was transferred to a three-necked round flask immersed in a thermostat water bath kept at $75^{\circ} \mathrm{C}$ and make up water was immediately added to adjust the total volume to $200 \mathrm{~mL}$. 
The polymerization was continued for $24 \mathrm{~h}$ under a nitrogen atmosphere while the reaction mixture was mechanically stirred at $100 \mathrm{rpm}$. The P(LMA-DVB) copolymer particles were washed repeatedly with double distilled water.

\subsection{Preparation of crosslinked P(LMA-DVB)/PGMA composite polymer particles}

P(LMA-DVB)/PGMA composite polymer particles were prepared by seeded polymerization of $1.5 \mathrm{~g}$ of GMA in presence of $3.0 \mathrm{~g}$ of P(LMA-DVB) seed particles employing $0.03 \mathrm{~g}$ of V-50 as initiator. Distilled water $(150 \mathrm{~g})$ was used as dispersion medium. The polymerization was carried out in a three-necked round bottomed flask set at $70^{\circ} \mathrm{C}$ in a thermostat water bath for $12 \mathrm{~h}$ in a nitrogen atmosphere. P(LMA-DVB)/PGMA composite polymer particles were washed by replacing the continuous phase with double distilled water following centrifugation prior to characterization.

\subsection{Preparation of crosslinked $\mathrm{P}(\mathrm{LMA}-\mathrm{DVB}) / \mathrm{PGMA} / \mathrm{Fe}_{3} \mathrm{O}_{4}$ composite polymer particles}

The surface of prepared P(LMA-DVB)/PGMA composite particles were modified to prepare magnetically doped $\mathrm{P}(\mathrm{LMA}-\mathrm{DVB}) / \mathrm{PGMA} / \mathrm{Fe}_{3} \mathrm{O}_{4}$ composite particles. The coprecipitation of $\mathrm{Fe}^{2+}(0.556 \mathrm{~g})$ and $\mathrm{Fe}^{3+}(0.6255 \mathrm{~g})$ from their alkali aqueous solution (molar ratio 1: 2) was carried out in presence of $2.5 \mathrm{~g}$ of P(LMA-DVB)/PGMA composite polymer particles dispersed in $150 \mathrm{~g}$ of water containing $20 \mathrm{~g}$ of $25 \% \mathrm{NH}_{4} \mathrm{OH}$ and. The precipitation was carried out in a three-necked round bottom flask under a nitrogen atmosphere at $60^{\circ} \mathrm{C}$ for $2 \mathrm{~h}$. Towards the end of precipitation process oleic acid $(0.019 \mathrm{~g})$ was added as stabilizer and the mixture was stirred for another $30 \mathrm{~min}$. The composite emulsion was black in color, washed repeatedly by magnetic separation and decantation.

\subsection{SEM observation}

A drop of latex dispersion was taken on a brush sample holder and dried under vacuum at room temperature. The dried sample was coated with $2 \mathrm{~A}^{\circ}$ thickness gold layer before observation under SEM.

\subsection{Thermogravimetric analysis (TGA)}

Thermal properties of the washed and dried powder were measured by heating samples under flowing nitrogen atmosphere from $30^{\circ}$ to $700^{\circ} \mathrm{C}$ at a heating rate of $20^{\circ} \mathrm{C} / \mathrm{min}$ and the weight loss was recorded.

\subsection{X-ray diffraction (XRD)}

The vacuum dried powder samples were placed on a glass sample holder. The XRD patterns of the powder samples were recorded by scanning X-ray diffractometer using $\mathrm{Cu}$ 
$\mathrm{K} \alpha$ radiation at room temperature. The intensities were measured at diffracted angle, (2theta) from $10^{\circ}$ to $90^{\circ}$ at a continuous scan rate of $1 \% \mathrm{~min}$.

\section{Results and Discussion}

Fig. 2 shows the SEM photographs of P(LMA-DVB) seed particles, P(LMADVB)/PGMA and $\mathrm{P}(\mathrm{LMA}-\mathrm{DVB}) / \mathrm{PGMA} / \mathrm{Fe}_{3} \mathrm{O}_{4}$ composite polymer particles. The average size and coefficient of variations (CVs) are $9.44 \mu \mathrm{m}$ and $54.88 \%$ for P(LMA-DVB) seed particles, $8.55 \mu \mathrm{m}$ and $20.31 \%$ for P(LMA-DVB)/PGMA and $11.26 \mu \mathrm{m}$ and $45.78 \%$ for $\mathrm{P}(\mathrm{LMA}-\mathrm{DVB}) / \mathrm{PGMA} / \mathrm{Fe}_{3} \mathrm{O}_{4}$ composite particles respectively. It is evident that seed particles have broad particle size distribution as normally observed for latex particles prepared by suspension polymerization [22-25]. Due to very high polydispersity index it is not wise to follow the increase in average particle size after seeded polymerization. The surface of $\mathrm{P}(\mathrm{LMA}-\mathrm{DVB})$ seed particles is relatively smooth. Following seeded polymerization with GMA the surface of P(LMA-DVB)/PGMA composite particles becomes rough with multiple protrusions. This normally happens when phase separation occurs during swelling of highly crosslinked polymer seed particles with monomer $[12,26,27]$. The surface heterogeneity increases further due to precipitation of iron oxide nanoparticles on the surface of P(LMA-DVB)/PGMA composite polymer particles. The interaction of epoxide ring on the surface of $\mathrm{P}(\mathrm{LMA}-\mathrm{DVB}) / \mathrm{PGMA}$ composite polymer particles was followed by coordination with $\mathrm{Fe}_{3} \mathrm{O}_{4}$ nanoparticles [13]. The formation of hydrogen bond between hydroxyl groups on the surface of iron oxide and ester groups of PGMA can also induce strong fixation of nanoparticles [28,29].

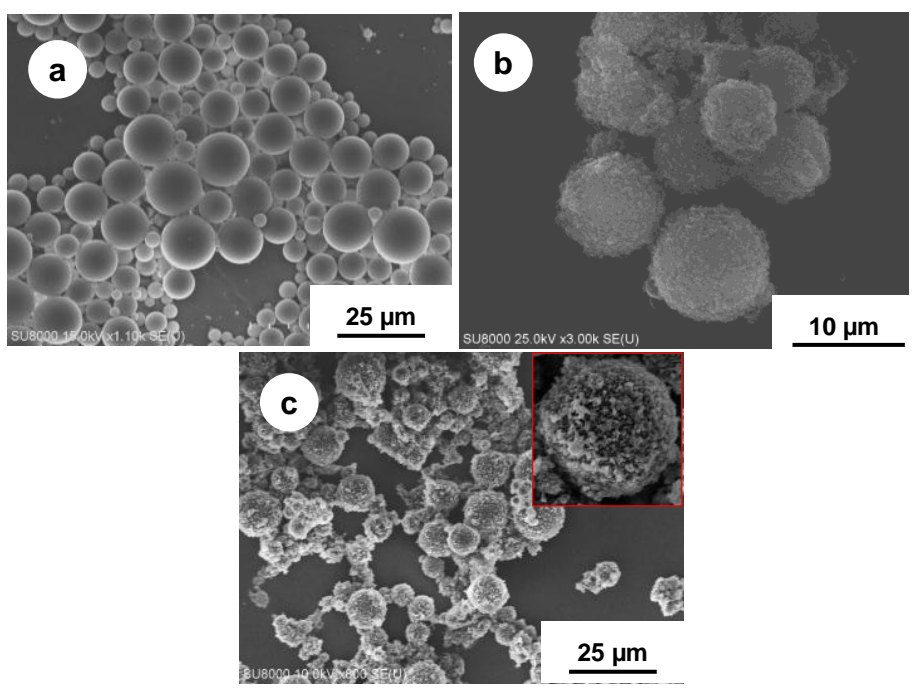

Fig. 2. SEM photographs of a) $\mathrm{P}($ LMA-DVB) seed particles, b) $\mathrm{P}($ LMA-DVB)/PGMA and c) $\mathrm{P}(\mathrm{LMA}-\mathrm{DVB}) / \mathrm{PGMA} / \mathrm{Fe}_{3} \mathrm{O}_{4}$ composite polymer particles. Fig. inset (c) shows magnified particle image. 
FTIR is a useful tool to identify the surface components of polymer particles. Fig. 3 shows the FTIR spectra of P(LMA-DVB) seed particles, P(LMA-DVB)/PGMA and $\mathrm{P}(\mathrm{LMA}-\mathrm{DVB}) / \mathrm{PGMA} / \mathrm{Fe}_{3} \mathrm{O}_{4}$ composite polymer particles. In the spectrum of $\mathrm{P}(\mathrm{LMA}-$ DVB) seed particles the characteristic sharp stretching vibration of ester carbonyl group derived from LMA appears at $1710 \mathrm{~cm}^{-1}$. The absorption signals in the range 2800-3000 $\mathrm{cm}^{-1}$ correspond to aliphatic and aromatic $-\mathrm{CH}$ stretching vibrations. Following seeded polymerization with GMA two characteristic absorption bands due to epoxide group appear at 991 and $915 \mathrm{~cm}^{-1}$ in $\mathrm{P}(\mathrm{LMA}-\mathrm{DVB}) / \mathrm{PGMA}$ composite polymer particles. Comparatively in the spectrum of $\mathrm{P}(\mathrm{LMA}-\mathrm{DVB}) / \mathrm{PGMA} / \mathrm{Fe}_{3} \mathrm{O}_{4}$ composite polymer particles the absorption bands at 551 and $465 \mathrm{~cm}^{-1}$ represent the characteristic stretching vibrations of $\mathrm{Fe}-\mathrm{O}$ bonds [30,31]. The intensity of the characteristic epoxide signals reduce following co-ordination of $\mathrm{Fe}_{3} \mathrm{O}_{4}$ nanoparticles. The shape of the broad signal averages at $3485 \mathrm{~cm}^{-1}$ changes following the precipitation of $\mathrm{Fe}_{3} \mathrm{O}_{4}$ nanoparticles on $\mathrm{P}(\mathrm{LMA}-\mathrm{DVB}) / \mathrm{PGMA}$ composite polymer particles. This signal attributes to the stretching vibration of surface water molecules and non-dissociated $-\mathrm{OH}$ groups derived from oleic acid or the envelope of hydrogen bonded surface $-\mathrm{OH}$ groups. The above results confirm the formation of epoxide functional composite polymer particles and subsequent doping with $\mathrm{Fe}_{3} \mathrm{O}_{4}$ nanoparticles.

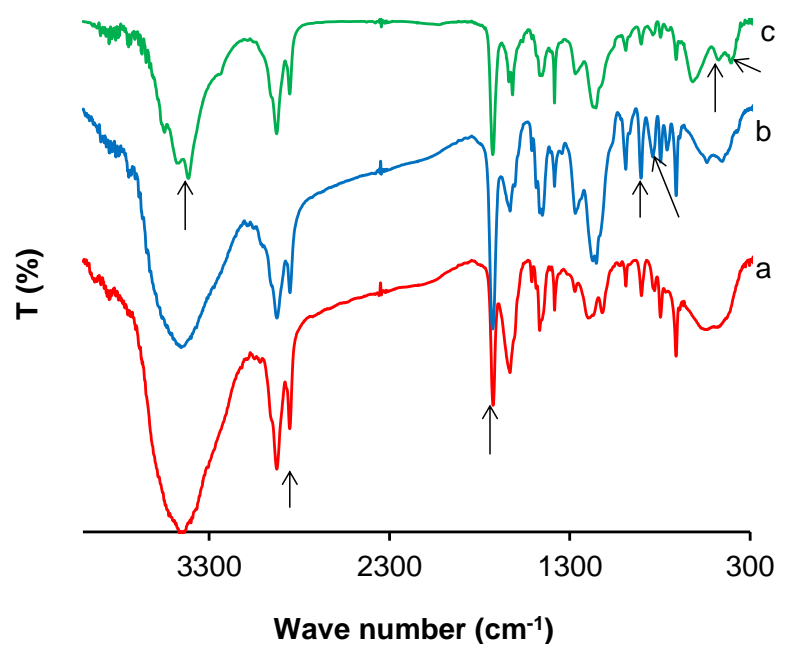

Fig. 3. FTIR spectra of a) P(LMA-DVB) seed particles, b) P(LMA-DVB)/PGMA and c) P(LMADVB)/PGMA $/ \mathrm{Fe}_{3} \mathrm{O}_{4}$ composite polymer particles.

Fig. 4 illustrates the comparative XRD diffraction patterns of P(LMA-DVB) seed particles, $\mathrm{P}(\mathrm{LMA}-\mathrm{DVB}) / \mathrm{PGMA}$ and $\mathrm{P}(\mathrm{LMA}-\mathrm{DVB}) / \mathrm{PGMA} / \mathrm{Fe}_{3} \mathrm{O}_{4}$ composite polymer particles. Both $\mathrm{P}(\mathrm{LMA}-\mathrm{DVB})$ seed particles and $\mathrm{P}(\mathrm{LMA}-\mathrm{DVB}) / \mathrm{PGMA}$ composite polymer particles exhibits broad and diffused characteristic amorphous signal at two theta value of $15^{\circ}$. In contrast the XRD pattern of magnetically doped P(LMADVB)/PGMA $/ \mathrm{Fe}_{3} \mathrm{O}_{4}$ composite polymer particles exhibits six characteristic sharp signals 
for iron oxide nanoparticles at $30.3^{\circ}, 35.6^{\circ}, 43.5^{\circ}, 54.0^{\circ}, 56.6^{\circ}$ and $62.46^{\circ}$ which can be assigned to (220), (311), (400), (422), (511) and (440) respectively according to the database of magnetite cited in JCPDS-International Centre (JCPDS Card: 19-0629) [32]. This XRD pattern of magnetically doped composite polymer particles additionally shows the broad diffuse amorphous signal for polymer segment as well. This result confirms the doping of $\mathrm{P}(\mathrm{LMA}-\mathrm{DVB}) / \mathrm{PGMA}$ composite polymer particles with $\mathrm{Fe}_{3} \mathrm{O}_{4}$ nanoparticles.

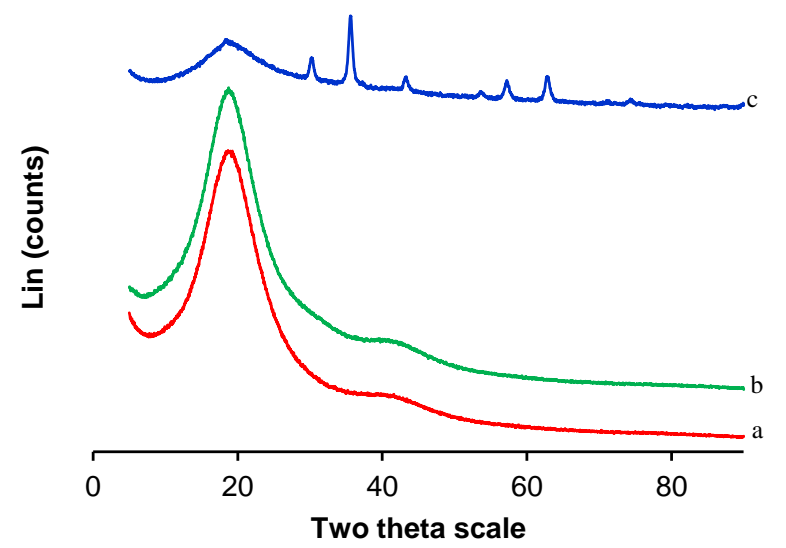

Fig. 4. XRD patterns of a) $\mathrm{P}($ LMA-DVB) seed particles, b) P(LMA-DVB)/PGMA and c) P(LMA$\mathrm{DVB} / \mathrm{PGMA} / \mathrm{Fe}_{3} \mathrm{O}_{4}$ composite polymer particles.

Fig. 5 shows mass loss against temperature from TG analyses measured for P(LMADVB) seed particles, $\mathrm{P}(\mathrm{LMA}-\mathrm{DVB}) / \mathrm{PGMA}$ and $\mathrm{P}(\mathrm{LMA}-\mathrm{DVB}) / \mathrm{PGMA} / \mathrm{Fe}_{3} \mathrm{O}_{4}$ composite polymer particles. As the temperature increases to $700^{\circ} \mathrm{C}$ the organic polymer in both $\mathrm{P}(\mathrm{LMA}-\mathrm{DVB})$ seed particles and P(LMA-DVB)/PGMA composite polymer completely burned away leaving no residual mass. Comparatively in magnetically doped P(LMADVB)/PGMA/ $/ \mathrm{Fe}_{3} \mathrm{O}_{4}$ composite polymer particles a residual mass of ca. $16 \%$ is left, which is assumed to be the percentage of iron oxide incorporated in composite particles. Irrespective of composition of latex particles, TGA thermograms exhibit two distinct mass loss regions. The initial mass loss in the region $200^{\circ}$ to $400^{\circ} \mathrm{C}$ is associated with the loss of associated moisture, degradation of oligomer and linear polymer chain. The second mass loss region starts at higher temperature $\left(450^{\circ} \mathrm{C}\right)$ corresponds to thermal degradation of crosslinked polymer. Overall the mass loss onset temperature in P(LMA-DVB)/PGMA composite polymer particles reduces to lower temperature possibly due to the decrease in crosslinking density following modification with PGMA layer. The doping of P(LMADVB)/PGMA composite polymer particles with inorganic $\mathrm{Fe}_{3} \mathrm{O}_{4}$ nanoparticles again increases the mass loss onset temperature and almost overlaps with crosslinked P(LMADVB) seed particles. These results suggest that the thermal stability of magnetically doped epoxide functional composite particles improved following the incorporation of inorganic $\mathrm{Fe}_{3} \mathrm{O}_{4}$ nanoparticles. 


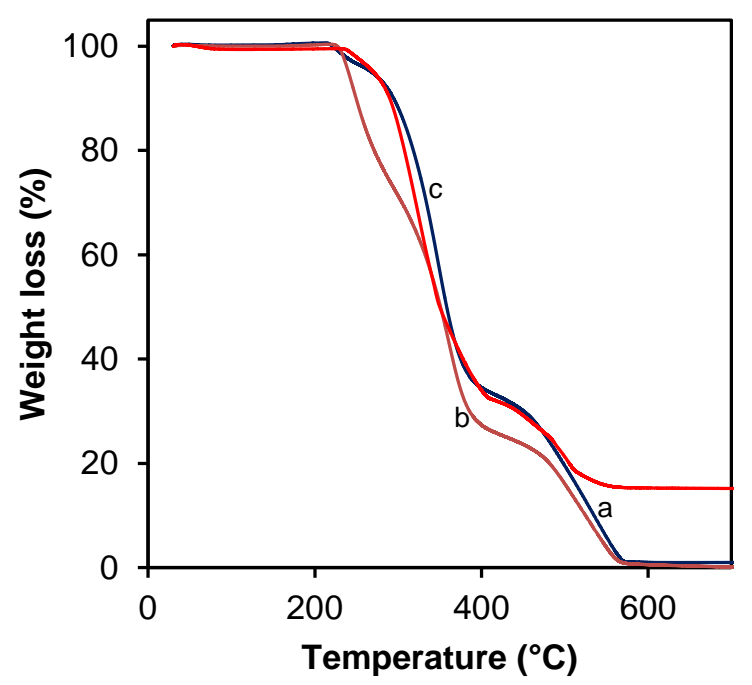

Fig. 5. TGA thermograms of a) $\mathrm{P}($ LMA-DVB) seed particles, b) P(LMA-DVB)/PGMA and c) $\mathrm{P}(\mathrm{LMA}-\mathrm{DVB}) / \mathrm{PGMA} / \mathrm{Fe}_{3} \mathrm{O}_{4}$ composite polymer particles.

A comparative EDX plot of P(LMA-DVB) seed particles, P(LMA-DVB)/PGMA and $\mathrm{P}(\mathrm{LMA}-\mathrm{DVB}) / \mathrm{PGMA} / \mathrm{Fe}_{3} \mathrm{O}_{4}$ composite polymer particles is shown in Fig. 6. The EDX spectra of $\mathrm{P}(\mathrm{LMA}-\mathrm{DVB})$ seed and $\mathrm{P}(\mathrm{LMA}-\mathrm{DVB}) / \mathrm{PGMA}$ composite polymer particles show signal due to $\mathrm{C}$ and $\mathrm{O}$ elements. However, the amount of $\mathrm{O}$ (atom \%) increases in P(LMA-DVB)/PGMA composite polymer particles from $6.6 \%$ to $21.9 \%$ after seeded polymerization with epoxide functional GMA monomer. The EDX spectrum of P(LMA$\mathrm{DVB}) / \mathrm{PGMA} / \mathrm{Fe}_{3} \mathrm{O}_{4}$ composite polymer particles indicates the presence of additional signal due to $\mathrm{Fe}(2.54$ atom \%) and the amount of $\mathrm{O}$ (atom \%) further increases to $23.49 \%$. These results confirm the modification of P(LMA-DVB) seed particles with epoxide functionality followed by doping with iron oxide nanoparticles.

Finally, the magnetic property of $\mathrm{P}(\mathrm{LMA}-\mathrm{DVB}) / \mathrm{PGMA} / \mathrm{Fe}_{3} \mathrm{O}_{4}$ composite polymer particles was investigated. The magnetically doped composite polymer particles can be separated up to $95 \%$ by employing magnetic field within one min (Fig. 7) leaving almost transparent supernatant. As the magnetic field is removed the magnetic particles again dispersed and the process was reversible. These results suggest that the prepared P(LMADVB)/PGMA $/ \mathrm{Fe}_{3} \mathrm{O}_{4}$ composite particles have strong magnetic property and can be separated from the treatment solution without employing time consuming separation process like centrifugation and sedimentation. 

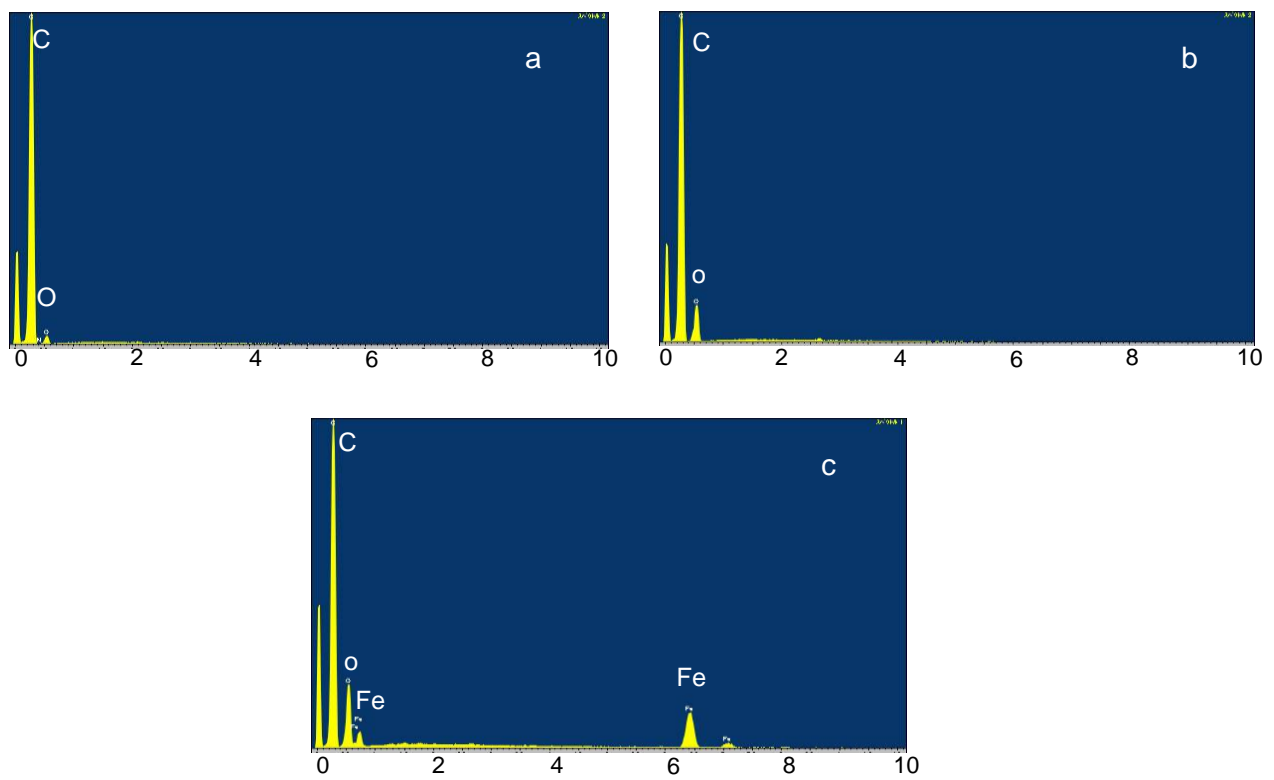

Fig. 6. EDX spectra of a) P(LMA-DVB) seed particles, b) P(LMA-DVB)/PGMA and c) P(LMA$\mathrm{DVB}) / \mathrm{PGMA} / \mathrm{Fe}_{3} \mathrm{O}_{4}$ composite polymer particles.

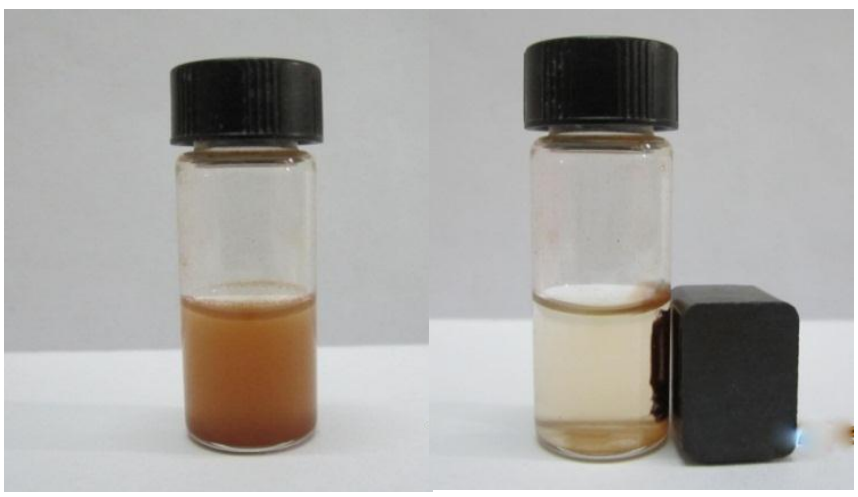

Fig. 7. Digital photographs of $\mathrm{P}(\mathrm{LMA}-\mathrm{DVB}) / \mathrm{PGMA} / \mathrm{Fe}_{3} \mathrm{O}_{4}$ composite particles before and after separation by employing magnetic field.

\section{Conclusion}

This investigation discusses the preparation of micron sized magnetically doped P(LMA$\mathrm{DVB} / \mathrm{PGMA} / \mathrm{Fe}_{3} \mathrm{O}_{4}$ composite polymer particles via a three-step process. In the first step $\mathrm{P}(\mathrm{LMA}-\mathrm{DVB})$ core particles were prepared by suspension polymerization. The surface of core particles was modified with reactive epoxide group by seeded polymerization with GMA. The fixation of $\mathrm{Fe}_{3} \mathrm{O}_{4}$ nanoparticles with epoxide group was finally done by 
precipitation of $\mathrm{Fe}^{2+}$ and $\mathrm{Fe}^{3+}$ from their alkali solution. The prepared composite polymer particles containing ca. $16 \% \mathrm{Fe}_{3} \mathrm{O}_{4}$ nanoparticles can be separated by applying magnetic field. These composite polymer particles can be useful for the treatment of wastewater discharged from industry.

\section{Acknowledgment}

The instrumental support from Central Science Laboratory, Rajshahi University is gratefully acknowledged.

\section{References}

1. H. F. Hernandez and K. Tauer, Synthesis of Polymers, ed. A.D. Schlüter et al. (Wiley-VCH, Weinheim, 2002) pp. 741.

2. W. Lau, Macromol. Symp. 182, 283 (2002). 3900(200206)182:1<283::AID-MASY283>3.0.CO;2-H

3. K. Tauer, A. M. I. Ali, U. Yildiz, and M. Sedlak, Polymer 46, 1003 (2005). https://doi.org/10.1016/j.polymer.2004.11.036

4. W. J. Xu, X. L. Zhu, Z. P. Cheng, and J. Y. Chen, J. App. Polym. Sci. 90, 1117 (2003).

5. Y. Y. Xu, H. Becker, J. Y. Yuan, M. Burkhardt, Y. Zhang, A. Walther, S. Bolisetty, M. Ballauff, and A. H. E. Muller, Macromol. Chem. Phys. 208, 1666 (2007). https://doi.org/10.1002/macp.200700097

6. K. Lindner and W. Saenger, Carbohydrate Res. 99, 103 (1982). https://doi.org/10.1016/S0008-6215(00)81901-1

7. E. Schneiderman and A. M. Stalcup, J. Chromatogr. B 745, 83 (2000). https://doi.org/10.1016/S0378-4347(00)00057-8

8. T. Loftsson and M. E. Brewster, J. Pharm. Sci. 85, 1017 (1996). https://doi.org/10.1021/js950534b

9. M. F. Islam, R. D. Jenkins, D. R. Bassett, W. Lau, and H. D. Ou-Yang, Macromolecules 33, 2480 (2000). https://doi.org/10.1021/ma9907845

10. R. Shabnam, K. Tauer, H. Minami, and H. Ahmad, J. Appl. Polym. Sci. 132, 41881 (2015). https://doi.org/10.1002/app.41881

11. R. Shabnam and H. Ahmad, Polym. Adv. Technol. 26, 408 (2015). https://doi.org/10.1002/pat.3468

12. R. Shabnam, M. A. J. Miah, M. K. Sharafat, M. A. Alam, H. M. T. Islam, and H. Ahmad, Arabian J. Chem. (2016). http://dx.doi.org/10. 1016/j.arabjc.2016.10.016

13. H. Ahmad, M. M. Alam, M. A. Rahman, H. Minami, and M. A. Gafur, Adv. Polym. Technol. 21645 (2015). https://doi.10.1002/adv.21645

14. S. Hokkanen, E. Repo, S. Lou, and M. Sillanpää, Chem. Eng. J. 260, 886 (2015). https://doi.org/10.1016/j.cej.2014.08.093

15. V. K. Sharma, T. J. McDonald, K. Hyunook, and K. G. Vijayendra, Adv. Colloid Interface Sci. 225, 229 (2015). https://doi.org/10.1016/j.cis.2015.10.006

16. M. Kumari, C. U. Pittman Jr., and D. Mohan, J. Colloid Interface Sci. 442, 120 (2015). https://doi.org/10.1016/j.jcis.2014.09.012

17. A. Strachota, K. Rodzén, F. Ribot, M. Trchová, M. Steinhart, L. Starovoytova, and E. Pavlova, Macromolecules 47, 4266 (2014). https://doi.org/10.1021/ma500507i

18. E. Bekyarova, E. T. Thostenson, A. Yu, H. Kim, J. Gao, J. Tang, H. T. Hahn, T. -W. Chou, M. E. Itkis, and R. C. Haddon, Langmuir 23, 3970 (2007). https://doi.org/10.1021/la062743p

19. M. Nakamura and K. Ishimura, Langmuir 24, 12228 (2008). https://doi.org/10.1021/la801950q 
20. M. S. Hossan, M. A. Rahman, M. R. Karim, M. A. J. Miah, and H. Ahmad, Am. J. Polym. Sci. 3, 83 (2013).

21. M. A. Alam, M. A. Rabbi, M. A. J. Miah, M. M. Rahman, M. A. Rahman, and H. Ahmad, J. Colloid Sci. Biotechnol. 1, 225 (2012). https://doi.org/10.1166/jcsb.2012.1019

22. F. C. Huang, C. H. Ke, C. Y. Kao, and W. C. Lee, J. App. Polym. Sci. 80, 39 (2001).

23. T. Zhao and D. Qiu, Langmuir 27, 12771 (2011). https://doi.org/10.1021/la2028912

24. J. H. Schutten, C. H. V. Hastenberg, P. Piet, and A. L. German, Macromol. Mat. Eng. 89, 201 (1980).

25. M. Okubo, H. Minami, and T. Komura, J. Appl. Polym. Sci. 88, 428 (2003). https://doi.org/10.1002/app.11720

26. D. J. Kraft, J. Hilhorst, M. A. P. Heinen, M. J. Hoogenraad, B. Luigjes, and W. K. Kegel, J. Phys. Chem. B 115, 7175 (2011). https://doi.org/10.1021/jp108760g

27. D. Kim, D. Y. Lee, K. Lee, and S. Choe, Macromol. Res. 17, 250 (2009). https://doi.org/10.1007/BF03218688

28. M. Ma, Q. Zhang, J. Dou, H. Zhang, D. Yin, W. Geng, and Y. Zhou, J. Colloid Interface Sci. 374, 339 (2012). https://doi.org/10.1016/j.jcis.2012.02.015

29. B. Liu, W. Zhang, F. Yang, H. Fang, and X. Yang, J. Phys. Chem. C 115, 15875, (2011). https://doi.org/10.1021/jp204976y

30. J. L. Zhang, R. S. Srivastava, and R. D. K. Misra, Langmuir 23, 6342 (2007). https://doi.org/10.1021/la0636199

31. M. Ma, Y. Zhang, W. Yu, H. Y. Shen, H. Q. Zhang, and N. Gu, Colloids Surf. A: Physicochem. Eng. Asp. 212, 219 (2003). https://doi.org/10.1016/S0927-7757(02)00305-9

32. X. Zheng, Q. Wang, Y. Jiang, and J. Gao, Ind. Eng. Chem. Res. 51, 10136 (2012). 